\title{
Leptospirosis en pediatría, un diagnóstico a tener en cuenta
}

\author{
Leptospirosis in pediatrics, a diagnosis to be considered
}

\author{
Andrés David Aranzazu Ceballos', Laura Apraez Henao² y Diana Cristina Ortiz Marín ${ }^{3}$
}

'Facultad de Medicina; Universidad Pontificia Bolivariana; Sede Escuela Ciencias de la Salud.

${ }^{2}$ Facultad de Medicina; Universidad San Martín sede Sabaneta, Colombia.

${ }^{3}$ Universidad CES y Universidad Pontificia Bolivariana. Medellín, Colombia.

Conflictos de interés: No se declaran conflictos de interés en el presente artículo.

Fuente de financiamiento: No se declara fuente de financiamiento para la construcción del presente artículo.

Recibido (segunda versión): 18 de octubre de 2020 / Aprobado: 20 de octubre de 2020

\section{Resumen}

La leptospirosis humana es una importante causa de enfermedad febril aguda que afecta con mayor frecuencia las zonas tropicales. Su principal reservorio es los roedores por lo que la infección está vinculada con factores de pobreza, déficit sanitario, actividades recreativas y laborales que favorecen el contacto con la orina de animales infectados, agua o suelos contaminados. Las infecciones por Leptospira spp tienen una presentación inespecífica desde cuadros asintomáticos hasta un compromiso multisistémico con alta mortalidad, siendo la sospecha clínica y la presencia de factores de riesgo las variables iniciales para el diagnóstico de la enfermedad. Entre los métodos disponibles para el diagnóstico microbiológico se destaca la observación directa, el cultivo, la reacción de polimerasa en cadena y la serología que permiten la confirmación de éste. El tratamiento de leptospirosis en niños se basa en medidas de soporte y en el inicio de antimicrobianos $\beta$-lactámicos o macrólidos. Las medidas de prevención de la enfermedad son fundamentales en la población expuesta al riesgo siendo recursos esenciales intervenciones generales, quimioprofilaxis y vacunación. El conocimiento, la consideración diagnóstica y el tratamiento oportuno en el paciente pediátrico, acelera la recuperación y limita la aparición de complicaciones que pueden impactar en la calidad de vida.

Palabras clave: leptospirosis; zoonosis; infecciones por espiroquetas; fiebre; niños.

\section{Introducción}

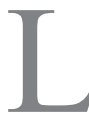

a leptospirosis es una zoonosis causada por espiroquetas del género Leptospira, común en países tropicales. Esta patología

ha recibido muchos nombres dependiendo de la zona geográfica donde se estudie, entre los más representativos: enfermedad de Weil, enfermedad de Swineherd, enfermedad transmitida por agua, fiebre de

\section{Abstract}

Human leptospirosis is an important cause of acute febrile disease that most frequently affects tropical areas. Its main reserve is rodents, so the infection is limited by factors of poverty, health deficit, recreational and work activities that favor contact with the urine of infected animals, contaminated water or soil. Leptospira spp infections have a non-specific presentation, ranging from asymptomatic to multisystem compromise with high mortality; being the clinical suspicion and the presence of risk factors the initial variables for the diagnosis of the disease. Among the available methods for microbiological diagnosis, direct observation, culture, polymerase chain reaction and serology that allows confirmation of this are highlighted. The treatment of leptospirosis in children is based on clinical support measures and the antibiotic initiation of $\beta$-lactams or macrolides. Disease prevention measures are fundamental in the population exposed to risk being essential resources general interventions, chemoprophylaxis and vaccination. The knowledge, diagnostic consideration, and timely treatment in pediatric patients accelerate recovery and limit the appearance of complications that can impact the quality of life

Keywords: leptospirosis; zoonosis; spirochete infections; fever; children.

los campos de arroz, entre otros ${ }^{1}$.

La infección resulta de la exposición directa o indirecta a un reservorio animal infectado, que lleva la espiroqueta en sus túbulos renales y la excreta por la orina. Muchos animales salvajes pueden ser reservorios, pero son las ratas cafés (Rattus norvegicus) la fuente de infección humana más importante ${ }^{2}$.

El diagnóstico clínico es impreciso, ya que, muchos de los síntomas 
y signos son inespecíficos, la mayoría de los casos son leves y auto-limitados, por lo que el paciente no suele consultar para la asistencia médica. El diagnóstico microbiológico se puede realizar mediante varias técnicas siendo la aglutinación microscópica el estándar de oro. El tratamiento es de soporte y el inicio temprano de la terapia antimicrobiana es clave para acortar la duración de la enfermedad ${ }^{2,3}$.

El conocimiento de esta enfermedad re-emergente en el mundo es fundamental en el personal de salud que atiende población pediátrica, debido a que, un diagnóstico precoz y un tratamiento oportuno impacta en la calidad de vida los pacientes. Un estudio publicado en Cuba en 2011, evaluó el nivel de conocimiento de leptospirosis en los pediatras del Hospital "William Soler", donde sólo $61 \%$ de los pediatras respondieron adecuadamente un cuestionario que evaluaba los conocimientos de esta enfermedad ${ }^{4}$.

Por esta razón, es objetivo del presente artículo de revisión entregar al lector información clara y concisa acerca de una enfermedad poco sospechada, sub-diagnosticada, pero con gran impacto en la epidemiología mundial, calidad de vida y desenlaces, con énfasis en los pacientes pediátricos.

\section{Epidemiología}

La leptospirosis es una zoonosis ampliamente diseminada y potencialmente mortal, que predomina en regiones tropicales. Esta enfermedad es endémica en Oceanía, Asia y América del Sur, pero en los últimos años ha aumentado el número de casos en Europa, América del Norte y África, considerándose una enfermedad mundialmente re-emergente. Las tasas de leptospirosis humana varían según la región, desde 0,5 por cada 100.000 habs. en Europa a 95 por cada 100.000 habs. en África ${ }^{1}$.

Según Leptospirosis Burden Epidemiology Group (LERG), se estima que hay aproximadamente 1,03 millones de casos en todo el mundo cada año, lo que resulta en 58.900 muertes. Sin embargo, en muchas zonas se presenta una sobre-notificación del evento por la presencia de otros síndromes febriles, ictéricos e ictero-hemorrágicos que dificultan el diagnóstico 5 .

La Organización Mundial de la Salud (OMS) reporta una incidencia de leptospirosis humana que va desde 1 caso por cada 100.000 habs. por año en climas templados a 10-20 casos por cada 100.000 habs. en climas tropicales húmedos, siendo esta condición climática característica en Centroamérica, Sudamérica y el Caribe ${ }^{6}$. En Latinoamérica se han registrado brotes en diferentes países como Brasil, Nicaragua y República Cooperativa de Guyana? Sin embargo, no se tiene un registro claro de los casos por la variación en los sistemas de vigilancia epidemio- lógica, ya que, no se conoce con claridad el inicio en la implementación de notificación obligatoria en diferentes países como El Salvador, Honduras y República Dominicana; a diferencia de Chile y Argentina quienes llevan un reporte desde el año 2002, y en Colombia desde 20073,8. El cambio climático global ha sido uno de los principales contribuyentes en la aparición de leptospirosis, como es el caso de brotes en América Central y América del Sur debido a inundaciones por el Fenómeno del Niño².

En Colombia, la leptospirosis es un evento de notificación obligatoria estimándose una seroprevalencia en humanos de aproximadamente 6-35\% según región de estudio ${ }^{9}$. La incidencia de la enfermedad no ha disminuido desde el año 2007 al 2020. Sin embargo, por cambios en la definición de caso se han registrado incidencias muy bajas de 0,20 por 100.000 habs. en el año 2019 y 0,13 en el $2020^{10}$. Según el Instituto Nacional de Salud en Colombia, en el último semestre de 2019, la población de niños afectados respecto al total de casos de leptospirosis en este período de tiempo representó el $23 \%$ de los casos, donde se encuentra mayormente asociada a con condiciones de pobreza y actividades en agua dulce ${ }^{11}$.

\section{Microbiología}

Leptospira spp pertenecen al grupo de las espiroquetas, bacteria gramnegativas, aerobias obligadas, altamente móviles, debido a que poseen dos flagelos. Tienen un diámetro de $0,1 \mu$ y una longitud de 6-20 $\mu$, pueden ser visualizadas en microscopio de campo oscuro, plata o coloración fluorescente. Tienen como principales proteínas dos flagelares: FlaA y FlaB, y su principal antígeno es los lipopolisacáridos (LPS).

Este patógeno es sensible a la pasteurización, (calor $/ 121^{\circ} \mathrm{C}$ por $15 \mathrm{~min}$ ) y se inactiva con hipoclorito de sodio al $1 \%$, formaldehido al $10 \%$ y etanol al $70 \%$; además, requiere de medios especiales para su crecimiento como Fletcher's, Ellinghausen-McCullough-JohnsonHarris (EMJH), o medio de polisorbato 80, observándose crecimiento en 2 semanas a 3 meses ${ }^{1}$. La familia Leptospiraceae incluye tres géneros, Leptospira, Turniella y Leptonema. El género Leptospira contiene 23 especies de las cuales 10 son patógenas, 6 con patogenicidad no clara y 7 no patógenas ${ }^{2}$ (Tabla 1 ).

\section{Modo de transmisión}

Los animales son hospederos definitivos, pueden ser asintomáticos o manifestar enfermedad leve en su gran mayoría, por lo que se ha llegado a proponer una relación comensal ${ }^{2}$. Los ratones representan el reservorio más importante para este patógeno, el que invade el borde en 


\begin{tabular}{|l|l|l|}
\hline \multicolumn{2}{|l|}{ Tabla 1. Especies del género Leptospira } \\
\hline Patógenas & Patogenicidad no clara & No patógenas \\
\hline L. alexanderi & L. broomii & L. biflexa \\
\hline L. alstonii & L. inadai & L. idoni \\
\hline L. borgpetersenii & L. fanei & L. meyeri \\
\hline L. interrogans & L. licerasiae & L. terpstrae \\
\hline L. kirschneri & L. venezuelansis & L. yanagawae \\
\hline L. kmetyi & L. wolffii & L. vanthielii \\
\hline L. mayottensis & & L. wolbachi \\
\hline L. noguchii & & \\
\hline L. santarosai & \\
\hline L. weilii & \\
\hline *Tabla elaborada por el autor. Fuente: Leptospirosis in Humans ${ }^{2}$. \\
\hline
\end{tabular}

*Tabla elaborada por el autor. Fuente: Leptospirosis in Humans².

cepillo del túbulo proximal renal del ratón, llevando a la depuración de manera intermitente o continua por la orina y convirtiéndolo en fuente de infección. Otros animales que se comportan como hospederos definitivos son los murciélagos, focas, ranas, sapos, castores, perros, caballos y ovejas, entre otros ${ }^{2}$.

La puerta de ingreso al ser humano, quien se comporta como un hospedero susceptible, se da generalmente por heridas o abrasiones en la piel o membranas mucosas como la conjuntiva, superficie oral y genital ${ }^{12}$. La vía de adquisición puede darse de manera directa mediante el contacto con el animal o sus secreciones, o por vía indirecta por medio del contacto con aceite o agua contaminada con las secreciones animales. En casos extremadamente inusuales se ha descrito transmisión entre humanos mediante vía sexual, lactancia materna, transplacentaria o consumo de drogas intravenosas ${ }^{13}$.
Existen factores de riesgo ocupacionales o recreacionales, los que facilitan que la población expuesta al riesgo adquiera la infección (Tabla 2)2.

\section{Fisiopatología}

La leptospira inicia su proceso de infección ingresando a través de membranas mucosas o soluciones de continuidad de la piel, alcanza al torrente sanguíneo logrando su diseminación hematógena y permanencia durante la llamada fase leptospirémica de la enfermedad, lo que se extiende por primeros 8 días ${ }^{14}$.

Se han descrito diferentes factores de adherencia como las proteínas de membrana externa (outer membrane protein-OMP en inglés) de especies patógenas como Lsa21/32/63 y LipL32/53 que se adhieren a la fibronectina, laminina y colágeno tipo $1 \mathrm{~V}$. Otros elementos adicionales con acción en la adherencia del hospedero son las proteínas similares a inmunoglobulinas (LigA y B). Adicionalmente a las proteínas de membrana, Leptospira spp posee un arsenal de enzimas invasoras como colagenasas y metaloproteasas, que permiten la rápida invasión del tracto sanguíneo, difusión a los órganos blanco y eliminación por la orina ${ }^{15}$.

Este microorganismo es reconocido por la respuesta inmune innata que inicia con el reconocimiento de los antígenos de Leptospira spp mediante los Patrones Moleculares Asociados a Patógenos (Pathogen-associated molecular patterns-PAMPS en inglés) y Receptores de Reconocimiento de Patógenos (Pathogen Recognition Receptors-PRRs en inglés), donde se encuentran los Receptores Tipo Toll (Toll like receptors-TLR en inglés), que activan la respuesta mediante el Factor Nuclear Potenciador de las Cadenas Ligeras Kappa de las Células B Activadas (Nuclear Factor kB-NF-KB en inglés) y Activador de proteína 1 (AP-1), aumentando la producción de

Tabla 2. Factores de riesgo para adquirir leptospirosis

Factores de riesgo ocupacionales

- Veterinarios

- Trabajadores de plantas de sacrificio (faenadoras)

- Trabajadores de granja

- Trabajadores en refugios animales

- Científicos

- Tecnólogos que realizan experimentos con animales

- Militares
Factores de riesgo recreacionales y ambientales

- Personas que viven en países tropicales

- Pobre servicio de saneamiento

- Condiciones de pobreza

- Exposición a roedores en los hogares

- Deportes en aguas estancadas

- Contacto con animales domésticos

- Temporadas de lluvia

- Industrialización

*Tabla elaborada por el autor. Fuente: Leptospirosis in Humans². 
prostaglandinas, óxido nítrico y citoquinas como el Factor de Necrosis Tumoral (Tumor Necrosis Factor-TNF en inglés), interferón y las interleuquinas (IL) 1B, 6 y 12 16-18.

Uno de los mayores factores de virulencia es la producción de endotoxinas, entre ellas los LPS, que son reconocidos por TLR2/4 y se relacionan con la respuesta pirogénica, endotóxica y toxicidad hepática directa (inductor de ictericia) ${ }^{15}$. Las hemolisinas, además de los LPS, inducen una amplia respuesta inflamatoria con producción de IL-1 $\beta$, IL-6 y FNT llevando a aumento de la permeabilidad vascular, inhibición del factor activador de plaquetas (Platelet Activating Factor-PAF en inglés) lo que origina coagulopatía y hemorragia masiva ${ }^{15}$.

El marcador principal de la leptospirosis grave, fisiológicamente hablando, es la tormenta de citoquinas, determinante de la respuesta inflamatoria sistémica que se presenta en estos casos; las principales citoquinas involucradas son la IL-1 $\beta$, IL-6, IL-8, lL-10 y el FNT- $\alpha$. En la Figura 1, se esquematiza las diferentes respuestas sistémicas durante la leptospirosis ${ }^{15}$.

La respuesta inmune adaptativa, se caracteriza por depuración de la leptospira en sangre y por un aumento en los títulos de anticuerpos, los cuales son detectables por distintas pruebas que serán descritas a lo largo de la revisión. En la fase febril y la fase inmune de la enfermedad se produce un daño importante a los tejidos, que puede perpetuar el compromiso multiorgánico ${ }^{2}$.

Tres órganos son los principales blancos de la leptospirosis en el humano, el primero es el hígado describiéndose congestión de sinusoides, distensión del espacio de Disse o espacio perisinusoidal, daño hepatocelular y apoptosis ${ }^{18}$, sobre el tejido pulmonar se ha encontrado hemorragia y petequias en la superficie alveolar y a nivel renal se ha descrito desde una disfunción renal no oligúrica a lesión renal aguda grave, como marcador del síndrome de Weil, adicionalmente necrosis tubular con distensión del lumen tubular y cilindros hialinos ${ }^{19}$.

\section{Manifestaciones clínicas}

La leptospirosis presenta una gran variedad de manifestaciones clínicas que pueden ir desde una enfermedad leve y auto-limitada hasta una enfermedad fulminante que compromete la vida. Generalmente, los signos y síntomas de la leptospirosis son inespecíficos, por lo cual, en muchos casos, no es la primera sospecha clínica durante el curso de un síndrome febril. La enfermedad tiene una fase inicial de septicemia seguida de una fase inmune en la que aparecen los síntomas de gravedad ${ }^{2}$. En la población infantil, se ha referido un curso clínico más grave que en los adultos; por ejemplo, en el año 2001, durante un brote en Mumbai (India), 32\% de los niños tenían leptospirosis grave ${ }^{12}$.

Se han descrito tres períodos clínicos de leptospirosis: incubación, septicémico/inmune y de recuperación ${ }^{2}$. El período de incubación, generalmente tiene un curso que dura entre 7-12 días (3-90 días)². Esta fase varía según la cantidad de inóculo infectante expuesto y el portal de entrada al organismo, pero no se ha determinado que tenga significancia pronóstica ${ }^{20}$.

La fase septicémica es caracterizada por una infección sistémica aguda, es de inicio abrupto con fiebre intermitente $\left(38-40^{\circ} \mathrm{C}\right)$, escalofríos, cefalea (de alta intensidad, con fotofobia), mialgias (localizadas en músculos gastrocnemios y dorsal baja), artralgias, hemorragia e hiperemia conjuntival (común en leptospirosis y no en otras patologías), exantema macular pre-tibial, tos no productiva, náuseas, vómitos, diarrea, dolor abdominal (colecistitis acalculosa o pancreatitis), ictericia, sangrado, poliuria y oliguria ${ }^{2}$. Esta fase termina en el plazo de 4 a 7 días, donde la mejoría clínica y la defervescencia coinciden con la desaparición de la leptospira en sangre, líquido cefalorraquídeo (LCR) y otros tejidos, con excepción del humor acuoso y el parénquima renal ${ }^{20}$.

La fase inmune se inicia con el aumento de los títulos de anticuerpos IgM y la presencia de leptospira en orina,

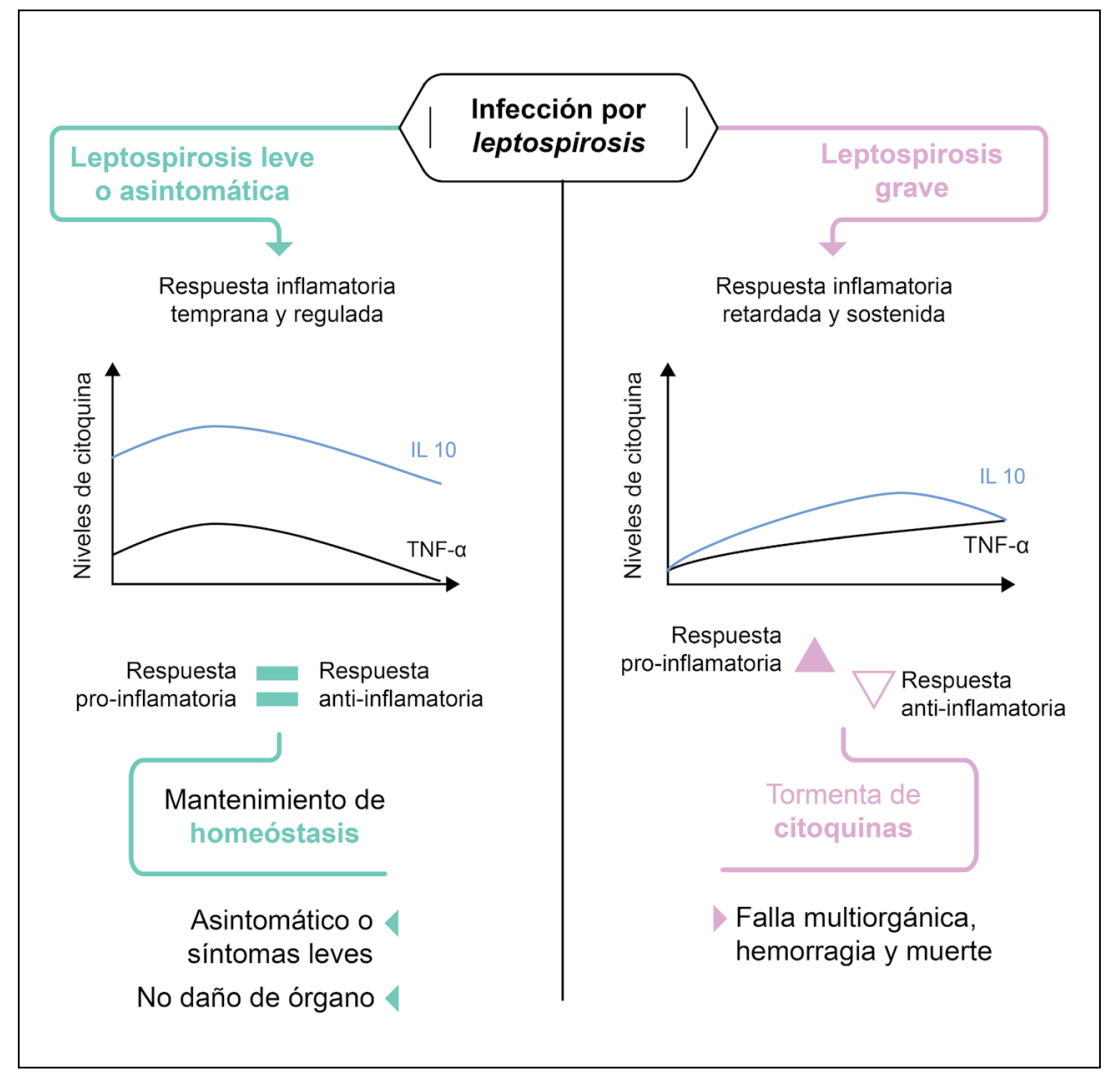

Figura 1. Relación entre respuesta inflamatoria sistémica y manifestaciones clínicas en la leptospirosis. En la leptospirosis grave se evidencia una respuesta inflamatoria exagerada con altos niveles de FNT- $\alpha$ e IL-1 $\beta$, lo que se conoce como tormenta de citoquinas. *FNT: factor de necrosis tumoral, IL: interleuquina. 
la cual comienza aproximadamente el día 4 de enfermedad y se extiende hasta el día 30 . Se caracteriza por la aparición, nuevamente, de fiebre y compromiso multiorgánico (hígado, riñón, meninges). Adicionalmente se puede presentar falla hepática aguda, lesión renal aguda, sangrado digestivo, hemorragia pulmonar, síndrome de dificultad respiratoria aguda (SDRA), uveítis, meningitis aséptica, mielitis transversa, síndrome de Guillain-Barré, miocarditis y rabdomiólisis, entre otros ${ }^{2,21}$. La leptospiruria es prevalente y continúa presentándose hasta un mes después de la primoinfección ${ }^{20}$.

La fase de recuperación se alcanza con un adecuado manejo de soporte. La mayoría de los pacientes se recuperan completamente, incluso quienes requieren diálisis para su tratamiento. En aproximadamente 30\% de los pacientes puede aparecer un síndrome denominado post-leptospirosis, caracterizado por debilidad, mialgias y cefalea ${ }^{2}$.

Clínicamente, la leptospirosis también puede ser clasificada según la presencia de ictericia, lo que se va a relacionar directamente con el curso clínico, presentación y complicaciones.

La leptospirosis anictérica representa $90 \%$ de todos los casos de leptospirosis en pediatría ${ }^{20,22}$. Tiene un inicio abrupto en fase septicémica, caracterizado por fiebre, mialgias, cefalea, hiperemia o hemorragia conjuntival, dolor abdominal, náuseas, emesis, visceromegalias, exantema polimorfo, mialgias, artralgias, malestar general, tos, dificultad respiratoria, expectoración sanguinolenta y, raramente, postración y colapso circulatorio. Los síntomas mejoran generalmente hacia el final del día 7, el paciente no experimenta enfermedad bifásica y la mortalidad es infrecuente. Cuando se presenta la fase inmune, el marcador de inicio es la meningitis que se refleja con pleocitosis ( $80 \%$ de los casos), con o sin síntomas meníngeos, uveítis, exantema polimorfo o cefalea ${ }^{2,22,23}$

La leptospirosis ictérica (también denominada síndrome de Weil $)^{2,20}$, se caracteriza por una presentación grave que lleva a una disfunción renal, hepática, colapso vascular, hemorragia intensa, alteración de la conciencia y una alta tasa de mortalidad (5 a 40\% $)^{24}$. En esta forma evolutiva, la fiebre puede persistir sin defervescencia entre las fases septicémica e inmune. El marcador de esta forma de presentación es la ictericia a expensa de la bilirrubina directa e indirecta, alcanzando su pico al día 7 del inicio de la enfermedad; este hallazgo puede estar acompañado de elevaciones modestas de aminotransferasas, donde raramente exceden $200 \mathrm{U} / \mathrm{L}$. Inusualmente la causa de mortalidad en los pacientes es el compromiso hepático ${ }^{2}$.

El compromiso renal es caracterizado por insuficiencia renal no oligúrica, asociada a hipocalemia. Se puede observar valores de nitrógeno ureico menor de $100 \mathrm{mg} / \mathrm{dL}$ y valores de creatinina entre 2 a $8 \mathrm{mg} / \mathrm{dL}$; en casos graves progresarán a requerimiento de terapia de reemplazo renal.
Durante la fase aguda se puede detectar trombocitopenia no asociada con coagulación intravascular diseminada, que progresa con el compromiso renal. En la biopsia se puede evidenciar nefritis intersticial o glomerulonefritis ${ }^{2,8}$.

El síndrome de hemorragia pulmonar grave es una forma de presentación que puede ocurrir en ausencia de compromiso hepático y renal. Se caracteriza por hemoptisis masiva la cual puede manifestarse con los accesos de tos, aunque la hemorragia puede ser inaparente hasta que el paciente es intubado. La radiografía de tórax se puede correlacionar con la presentación clínica, ya que, se relaciona con opacidades alveolares confluentes o patrón de "copo de nieve" en la periferia del parénquima pulmonar $^{25-27}$.

Se ha descrito, de igual manera, compromiso cardíaco en las formas más graves de presentación. Cuando se utiliza monitoreo electrocardiográfico continuo se puede evidenciar arritmias cardiacas como fibrilación y flutter atrial, taquicardia y extrasístoles ventriculares. El colapso cardiovascular y la falla cardiaca aguda ocurren en pocos casos, pero sin el soporte clínico adecuado pueden llevar a la muerte. A nivel histológico se ha descrito miocarditis, aortitis y arteritis coronaria ${ }^{19}$.

La meningitis aséptica se puede presentar en menos de $25 \%$ de todos los casos de leptospirosis ${ }^{2}$ con clínica de cefalea de intensidad grave, fotofobia y rigidez de nuca. La alteración del sensorio es más común en niños que en adultos; sin embargo, sólo $50 \%$ de los casos tienen manifestaciones meníngeas. Los hallazgos en el LCR muestran presión de apertura elevada, pleocitosis linfocítica (menor a 500 céls $/ \mathrm{mm}^{3}$ ), recuento normal o elevado de proteínas (más de $300 \mathrm{mg} / \mathrm{dl}$ ) y glucorraquia normal. Algunos pacientes pueden estar anictéricos lo que dificulta el diagnostico ${ }^{4}$.

La insuficiencia hepática que se presenta en los pacientes con leptospirosis generalmente es reversible. Se caracteriza por un patrón colestásico, con hiperbilirrubinemia conjugada, elevación leve a moderada de transaminasas y elevación mínima de la fosfatasa alcalina. La ictericia que ocurre en la leptospirosis no está asociada con necrosis hepato-celular si no con el compromiso canalícular; la función hepática vuelve a la normalidad después de la recuperación ${ }^{2}$.

En un estudio en Colombia, se analizaron 74 casos de leptospirosis en niños que ingresaron al servicio de urgencias por cuadro febril en cuatro hospitales ubicados en una zona endémica. Los pacientes fueron confirmados con cultivo positivo, aumento en los títulos de aglutinación microscópica (MAT) o una prueba de inmunofluorescencia (IFI) en la fase convaleciente. Fueron clasificados como graves $29,7 \%$ de los casos, donde los signos y síntomas predominantes eran ictericia (45,5\%), dolor abdominal (40,9\%), manifestaciones hemorrágicas $(40,9 \%)$ y hepatomegalia $(31,8 \%)^{28}$. 
En otro estudio realizado en Salvador (Brasil), de cohorte prospectivo, que incluyó 326 pacientes adultos, se identificaron algunos factores de riesgo para mortalidad, con su respectivo Odds Ratio (OR) e intervalos de confianza (IC), entre los que se destacan: alteración del estado mental OR 9,12 (IC 4,28-20,3), oliguria OR 5,28 (IC 2,45-12,0), dificultad respiratoria OR 2,56 (IC $1,12-5,8$ ), opacidad alveolar en radiografía OR 7,3 (IC 1,7-31,7), anormalidades electrocardiográficas OR 5,95 (IC $1,4-24,8$ ) y leucocitosis $>12.900 / \mathrm{mm}^{3}$ OR 2,54 (IC $1,8-3,5)^{29}$.

\section{Diagnóstico}

El diagnóstico y la confirmación microbiológica de la leptospirosis en la población pediátrica se convierte en un desafío. El enfoque diagnóstico empieza con la sospecha clínica, la que debido a su presentación clínica inespecífica puede llevar a pensar inicialmente en otros diagnósticos, por lo que se requieren pruebas de laboratorio para confirmar o aumentar la probabilidad diagnóstica ${ }^{30}$. En la Tabla 3 se muestran los exámenes de laboratorio requeridos inicialmente y los posibles hallazgos.

Para realizar la confirmación etiológica de la leptospirosis, existen métodos de detección directa e indirecta. Lo métodos de detección directa se caracterizan por la observación del microorganismo a través de microscopio, el aislamiento de la espiroqueta o la detección de su ADN mediante reacción de polimerasa en cadena (RPC) $)^{30}$.

La visualización directa de la espiroqueta se puede realizar a partir de muestras de sangre, orina y LCR, las cuales son confirmadas mediante la observación de la espiroqueta en el microscopio de campo oscuro. Este método generalmente no es empleado de forma rutinaria, debido a su baja sensibilidad y baja especificidad (se les describe 40,2 y $61,5 \%$, respectivamente) debidas a la confusión con diferentes artefactos (fibras proteicas) y la poca disponibilidad ${ }^{22,30}$.

El uso de técnicas con análisis de RPC o de amplificación isotérmica mediada por bucle (Loop-Mediated Isothermal Amplification-LAMP en inglés) han sido desarrolladas para una detección rápida y precisa de leptospira, pero no han sido ampliamente evaluadas en estudios clínicos prospectivos. Se puede realizar RPC a partir de suero, orina, humor acuoso, LCR y tejidos postmortem $^{31,32}$. Estos análisis tienen como ventaja la confirmación del diagnóstico en poco tiempo durante la fase leptospirémica de la enfermedad, antes de la aparición de la respuesta inmune, cuando el inicio del tratamiento tiene mayor beneficio clínico. El rendimiento de la RPC en muestra obtenida en la fase aguda es mayor que en los cultivos, alcanzando una sensibilidad de 100\% y especificidad de $93 \% \%^{30,33}$.
Medios de cultivo especiales como el EMJH (Ellinghausen-McCullough-Johnson-Harris) o Fletcher, requeridos para el crecimiento de leptospira, están disponibles comercialmente. Los cultivos son generalmente incubados a $30^{\circ} \mathrm{C}$ por algunas semanas debido a su crecimiento lento (13 semanas) ${ }^{2}$. La leptospira puede ser aislada de muestras de sangre, LCR y liquido de diálisis peritoneal, si se toma muestra en los primeros 10 días de la enfermedad, mientras el paciente permanezca febril y no se haya iniciado tratamiento antimicrobiano. El rendimiento del aislamiento con una muestra de orina se ha determinado después de la primera semana de enfermedad.

A partir del aislamiento en el cultivo de leptospira, se pueden utilizar técnicas serológicas tradicionales ${ }^{22}$ o técnicas moleculares recientemente descritas, con gran potencial de aplicación, para la detección de las distintas especies. Entre las pruebas moleculares utilizadas se encuentran Restricción de fragmento de longitud del polimorfismo (Restriction Fragment Length Polymorphism-RFLP en inglés), Electroforesis en Gel de Campo Pulsado (Pulsed-Field Gel ElecrophoresisPFGE en inglés), Secuencia de Tipificación de Múltiples

\begin{tabular}{|c|c|}
\hline Parámetro & Hallazgo \\
\hline Hemograma & Leucocitosis, leucopenia, trombocitopenia \\
\hline PCR y/o VHS & Aumento \\
\hline lonograma & $\begin{array}{l}\text { Hiponatremia e hipocalemia relacionadas al compromiso renal subya- } \\
\text { cente }\end{array}$ \\
\hline Uro-análisis & $\begin{array}{l}\text { Se puede evidenciar proteinuria, piuria, cilindros granulosos y hematuria } \\
\text { microscópica }\end{array}$ \\
\hline Función renal & Aumento del NU y creatininemia \\
\hline CPK & Elevación \\
\hline Función hepática & $\begin{array}{l}\text { Aumento de transaminasas (generalmente }<2.00 \mathrm{U} / \mathrm{L} \text { ) e hiperbilirrubi- } \\
\text { nemia directa e indirecta }\end{array}$ \\
\hline LCR & $\begin{array}{l}\text { Pleocitosis neutrofílica (fase temprana) y linfocítica (fase tardía). Protei- } \\
\text { norraquia (hasta } 300 \mathrm{mg} / \mathrm{dL} \text { ) y glucorraquia normal }\end{array}$ \\
\hline Radiografía de tórax & $\begin{array}{l}\text { - Infiltrado confluente o consolidación masiva, que representa áreas de } \\
\text { hemorragia pulmonar } \\
\text { - Opacidades pequeñas, irregulares como "copos de nieve" en la peri- } \\
\text { feria } \\
\text { - Opacidades solitarias con márgenes mal definidos }\end{array}$ \\
\hline
\end{tabular}

*Tabla elaborada por el autor. **PCR: proteína C reactiva, VHS: velocidad de hemosedimentación, CPK: creatin-fosfokinasa, LCR: líquido cefalorraquídeo. Fuente: Diagnostic accuracy of real-time PCR assays targeting $16 \mathrm{~S}$ rRNA and lipl32 genes for human leptospirosis in Thailand: A casecontrol study ${ }^{30}$. 
Locus (Multilocus Sequence Typing -MLST en inglés), Análisis de Repetición en Tándem de Múltiples Locus (Multiple-Locus Variable-Analysis- MLVA en inglés), los cuales se aplican en el análisis epidemiológico de la leptospirosis ${ }^{2,33}$. Además de la tipificación molecular, la desorción/ionización láser asistida por matriz (MALDITOF), se ha utilizado de igual forma para el aislamiento de leptospira ${ }^{30}$

Los métodos de detección indirecta agrupan la microaglutinación, ELISA (enzimo-inmunoanálisis de adsorción), la aglutinación por látex y la aglutinación microscópica. Estos permiten la detección de anticuerpos IgM específicos de leptospira mediante una reacción antígeno-anticuerpo 5 a 7 días después del inicio de los síntomas, al final de la fase aguda ${ }^{22}$.

La aglutinación microscópica (Microscopic Agglutination Test-MAT en inglés), es la prueba de referencia de OMS. Se caracteriza por la reacción entre una suspensión antigénica de serogrupos de leptospira con el suero del paciente, se observa aglutinación en la microscopia de campo oscuro, dando el resultado a través de diluciones en forma de títulos. Un caso confirmado de leptospirosis es definido por un aumento en los títulos de MAT de 4 veces cuando se comparan los títulos de fase aguda e inmune o la presencia de títulos mayores a 1:800 en presencia de síntomas compatibles de infección. Esta prueba tiene una sensibilidad y especificidad alrededor de $90 \%{ }^{6}$. Esta prueba es restringida a laboratorios de referencia; puede ser difícil de interpretar debido a la reacción cruzada con anticuerpos de otras enfermedades como sífilis, Lyme, hepatitis viral, infección por virus de inmunodeficiencia humana (VIH), enfermedades autoinmunes o entre los mismos serogrupos de leptospira, por lo que no debe ser ampliamente utilizado para la identificación de éstos. No obstante, puede tener valor epidemiológico en determinar exposición potencial a reservorios animales ${ }^{2}$.

La prueba de ELISA (ensayo por inmunoabsorción ligado a enzimas) permite la detección de $\operatorname{IgM}$ e $\operatorname{IgG}$ a partir de preparados de L. biflexa o de algunas especies patógenas. Las muestras son tomadas en la fase convaleciente y siempre requiere la confirmación del resultado por MAT. Los resultados son generalmente rápidos $(1 \mathrm{a}$ $2 \mathrm{~h}$ ), además de que presenta una sensibilidad de $90 \%$ y una especificidad de $88-95 \%$. Sus resultados pueden afectarse en regiones endémicas debido a infecciones previas por leptospira ${ }^{6,22}$.

La detección de leptospira por inmunofluorescencia se basa en el reconocimiento de la proteína de superficie OmpL54 mediante anticuerpos. Anticuerpos secundarios marcados con radioisótopos se unen al complejo antígenoanticuerpo, originando una reacción colorimétrica y su lectura se hace mediante la observación con microscopio de fluorescencia ${ }^{30}$.

Existen otras pruebas diagnósticas rápidas como aglutinación por látex, flujo lateral, aglutinación, hemaglutinación realizadas por medio de tiras reactivas o plataforma de plato dual, que pueden ser aplicadas en ciertas circunstancias, pero siempre se deben confirmar los resultados con las pruebas de referencia ${ }^{2}$.

En resumen, y teniendo en cuenta los métodos diagnósticos descritos anteriormente, la recomendación ante la sospecha de un caso de leptospirosis es realizar al

Tabla 4. Definición de caso sospechoso y caso confirmado de leptospirosis en Colombia

Tipo de caso Características

Sospechoso

Paciente con fiebre $\left(>38^{\circ} \mathrm{C}\right)$ en las últimas tres semanas + dos o más de los siguientes síntomas o signos: cefalea, mialgia, conjuntivitis, artralgias, vómitos, diarrea, dorsalgia, escalofríos o fotofobia, más signos de manifestación multi-orgánica si hay progresión de la enfermedad

Antecedentes epidemiológicos sugestivos

- Exposición a inundaciones, lodo o contacto con aguas estancadas (pozos, arroyos, lagos o ríos)

- Se consideran actividades con riesgo laboral

Confirmado por laboratorio

$$
\begin{aligned}
& \text { Seroconversión en muestras pareadas mediante microaglutinación (MAT) mayor a 1:4 } \\
& \text { Títulos de MAT iguales o mayores a 1:400 en la primera muestra en los casos fatales } \\
& \text { miento antimicrobiano) } \\
& \text { Pruebas moleculares: detección de ADN mediante RPC en los casos de mortalidad. }
\end{aligned}
$$

Confirmado por nexo epidemiológico

Confirmación de los casos sospechosos sin posibilidad de toma de muestras a partir de casos confirmados por laboratorio, realizando asociaciones en persona, tiempo y lugar, teniendo en cuenta la exposición a la misma fuente de infección identificada para los casos confirmados

*Adaptado y modificado de Instituto Nacional de Salud. Informe de evento, leptospirosis 2017. **RPC: reacción de polimerasa de cadena, ADN: ácido desoxirribonucleico, LCR: líquido cefalorraquídeo 
momento de la presentación RPC y/o IgM por ELISA y si alguna de éstas dos pruebas es positiva, se recomienda el uso de MAT: un aumento en los títulos $>1: 4$ entre la muestra aguda y convaleciente es diagnóstico, al igual que una única muestra con títulos mayores a 1:400 ${ }^{11}$.

\section{Enfoque general}

El diagnóstico en Colombia se realiza siguiendo los lineamientos del Instituto Nacional de Salud (INS), el cual hace una revisión semanal de los casos reportados de leptospirosis debido a que ésta es una enfermedad de vigilancia epidemiológica de reporte obligatorio. En la Tabla 4 se muestra la definición de caso sospechoso y las herramientas con las que cuenta el país para la confirmación del diagnóstico ${ }^{11}$.

\section{Diagnóstico diferencial}

Debido a la amplia variedad de manifestaciones clínicas de la leptospirosis y las limitaciones que representa en los pacientes pediátricos el interrogatorio (especialmente en la etapa pre-verbal), múltiples enfermedades infecciosas pueden ser sospechadas inicialmente. En regiones tropicales de Colombia, Brasil, Ecuador, y Venezuela, las arbovirosis como el dengue, Zika o Chikungunya, pueden ser indistinguibles en fases iniciales debido a la presencia de cefalea, dolor retro ocular, fiebre alta, mialgias, artralgias ${ }^{2,20}$. En las formas de presentación del dengue grave, puede existir una diferencia en el compromiso hepato-celular el cual es mucho mayor en el dengue comparativamente hablando respecto a leptospirosis, pero en el contexto de choque o sangrado masivo no es posible la diferenciación. La presentación de malaria, originado por el género Plasmodium, comparte muchos síntomas generales iniciales y las formas graves de presentación, siendo predominantes la coagulopatía, compromiso hepático y choque en las formas graves. Otras enfermedades descritas también dentro del diagnóstico diferencial son la infección por Brucella spp, Borrelia spp, Rickettsia spp, virus de fiebre amarilla, Salmonella Typhi, Ehrlichia spp, virus influenza y hantavirus ${ }^{34}$.

\section{Tratamiento}

El pilar del tratamiento de la leptospirosis es la antibioterapia temprana, la que permite modificar el curso clínico de la enfermedad y llevar a resultados benéficos para el paciente. Se debe tener en cuenta que la mayoría de los casos son auto-limitados y se resuelven de forma espontánea $^{22}$.
La terapia de soporte y la monitorización clínica, de signos vitales y electrocardiográfica, es esencial para los pacientes con presentaciones moderadas a graves. Los pacientes que presenten lesión renal aguda no oligúrica e hipocalemia deben recibir un manejo enérgico con reposición de líquidos y suplementación de potasio para evitar la necrosis tubular aguda y complicaciones debido al trastorno del potasio. En pacientes en quienes la lesión renal progresa, el rápido inicio de hemodiálisis mejora el pronóstico de vida, llevando a recuperación completa de la función renal. Los pacientes que presentan compromiso pulmonar grave pueden requerir intubación orotraqueal y se deben manejar con estrategias de ventilación para evitar la lesión pulmonar ${ }^{20,22}$.

El tratamiento antimicrobiano va dirigido a acortar la duración de la enfermedad y mejorar los desenlaces clínicos. Si un paciente ingresa a un servicio de urgencias, con factores de riesgo y síntomas compatibles con leptospirosis, se debe iniciar antibioterapia empírica sin esperar la confirmación, ya que ésta puede tardar de días a semanas. Se ha descrito, y ha de tenerse presente, que $21 \%$ de los casos puede presentar la reacción de JarishHerxheimer, igual a observada en sífilis ${ }^{22}$. En los casos de enfermedad grave se recomienda manejo endovenoso con los medicamentos que hace referencia la Tabla 5 y en los casos leves los medicamentos que se mencionan en la Tabla $6^{1}$.

\section{Tabla 5. Tratamiento antimicrobiano en casos de leptospirosis grave}

\begin{tabular}{ll}
\hline Fármaco & Dosis y duración \\
Penicilina G cristalina & $100.000-300.000 \mathrm{U} / \mathrm{kg} /$ día IV, fraccionado cada 4-6 h, por 7 días \\
Doxiciclina & $4 \mathrm{mg} / \mathrm{kg} /$ día, fraccionado cada $12 \mathrm{~h}$, por 7 días \\
Ceftriaxona & $50-75 \mathrm{mg} / \mathrm{kg}$, cada $24 \mathrm{~h}$, por 7 días \\
Cefotaxima & Cefotaxima $150-180 \mathrm{mg} / \mathrm{kg} /$ día, fraccionado cada $8 \mathrm{~h}$, por 7 días \\
Azitromicina & Azitromicina $10 \mathrm{mg} / \mathrm{kg}$ inicial y luego $5 \mathrm{mg} / \mathrm{kg}$ día por 5 días \\
\hline *Tabla elaborada por el autor. Fuente: Redbook'.
\end{tabular}

\begin{tabular}{|c|c|}
\hline Fármaco & Dosis y duración \\
\hline Doxiciclina & $4 \mathrm{mg} / \mathrm{kg} / \mathrm{día}$, fraccionado cada $12 \mathrm{~h}$, por 7 días (en mayores de 8 años) \\
\hline Amoxicilina & $50 \mathrm{mg} / \mathrm{kg} / \mathrm{día}$, fraccionado cada $8 \mathrm{~h}$, por 7 días \\
\hline Azitromicina & Azitromicina $10 \mathrm{mg} / \mathrm{kg}$ inicial y luego $5 \mathrm{mg} / \mathrm{kg}$ día por 5 días en total \\
\hline
\end{tabular}




\section{Prevención}

Múltiples estrategias de prevención han sido propuestas para prevenir la infección, como medidas de protección en zonas de alto riesgo, inmunización y uso de quimioprofilaxis, que van a depender de las circunstancias ambientales y el grado de actividad humana ${ }^{22}$.

Las medidas de protección en zonas de alto riesgo de contagio con leptospirosis comprenden el uso de guantes, botas, protectores oculares en trabajadores con alto riesgo de exposición con secreciones directas o indirectas de animales infectados, como herramientas más efectivas. Otras estrategias como el control de roedores, la prevención de las inundaciones, la identificación y tratamiento de animales enfermos han sido descritas como efectivas ${ }^{2,22}$.

La inmunización de los animales de agricultura y domésticos, con una vacuna no replicativa, ha sido ampliamente implementada para prevenir la enfermedad y reducir la exposición humana. Esta vacuna previene la enfermedad, pero no la colonización renal, por lo que los animales vacunados aún pudieran depurar leptospira, en pocas cantidades, por la orina. Las serovariedades contenidas en las vacunas cambian según las especies animales a inmunizar; por ejemplo, la vacuna porcina y bovina contiene serovariedades Icterohemorragica, Canicola, Grippotyphosa, Pomona y Hardjo; comparada con la canina que contiene todas menos Hardjo $^{2,34}$

La vacuna para humanos no es ampliamente utilizada Una vacuna francesa (Spirolept ${ }^{\mathrm{TM}}$ ) que contiene el $L$. interrogans serovar Icterohaemorragiae cepa Verdun, células enteras, inactivada, aprobada para trabajadores con ocupaciones de alto riesgo ${ }^{35}$. El esquema se basa en dos dosis con 15 días de diferencia, un refuerzo 4 a 6 meses posterior a la primera dosis y refuerzos cada 2 años. $\mathrm{Su}$ efectividad es limitada, ya que, ofrece una cobertura restringida (un tercio de los serogrupos aislados) y tiene una inmunidad de corta duración ( 24 meses) ${ }^{1}$.

Una vacuna de células enteras, inactivada, con cepas vacunales 87, 169 y 108 de los serogrupos Leptospira canicola, L. copenhageni y L. mozdok respectivamente, desarrollada en el Instituto Finlay de Cuba (VaxSPIRAL $\left.{ }^{\circledR}\right)^{36}$, también aprobada, cuenta con un esquema de dos dosis separados de 6 semanas y con una eficacia de 78,1\% (IC95\%: 59,2-88,3\%).

El uso de estas dos vacunas ha sido reservada, no sólo para trabajadores de alto riesgo, sino también en respuesta a brotes epidémicos o desastres naturales, pero su eficacia no se ha probado en población pediátrica, por lo que su recomendación en esta edad no tiene sustento científico $^{37}$.

Desde 1986 hasta la fecha, los esfuerzos para la creación de una vacuna efectiva con altas tasas de inmunogenicidad, segura y efectiva de uso universal continúan en proceso, debido a la dificultad que entraña las características intrínsecas del género; Leptospira spp contiene un alto número de serogrupos (más de 230) lo que ha limitado el desarrollo de una vacuna universal. Investigaciones recientes han demostrado que los LPS y las OMP, principales factores de virulencia que interactúan con la respuesta inmune del hospedero, carecen de reactividad cruzada entre los diferentes serogrupos ${ }^{38}$.

Otro candidato vacunal extensamente estudiado a la fecha son las proteínas de leptospira similares a inmunoglobulinas ( $\mathrm{Lig}$ ). Las vacunas usando proteínas recombinantes LigA y LigB han demostrado un amplio rango de protección dependiendo de la composición de la vacuna, aunque todavía se encuentran en fase experimental y no han sido aprobadas para uso universal ${ }^{38}$.

Se ha propuesto la quimioprofilaxis pre y postexposición para personas quienes viven en ambientes endémicos, seguido de desastres naturales o con factores de riesgo ocupacionales para adquirir leptospirosis. A diferencia de los adultos, en quienes es clara la recomendación el uso de doxiciclina $200 \mathrm{mg}$ semanalmente (especialmente en personal militar previo a entrenamiento en la jungla), en los niños no hay una recomendación tan certera por sus ya conocidos efectos. Se ha propuesto el uso alternativo de azitromicina $(5 \mathrm{mg} / \mathrm{kg} / \mathrm{dosis})$ o amoxicilina $(50 \mathrm{mg} / \mathrm{kg} / \mathrm{dosis})$ una vez a la semana según plausibilidad biológica, pero sin un respaldo por estudios clínicos aleatorizados en esta población ${ }^{2}$. Con esta conducta, según datos extrapolados de adultos, se busca prevenir la gravedad, pero no se evita la infección por Leptospira $\mathrm{spp}^{2,39}$.

\section{Conclusiones}

La leptospirosis en pediatría representa una patología la mayoría de las veces sub-diagnosticada debido a que en muchas ocasiones no se tiene dentro del diagnóstico diferencial del enfoque del niño febril en regiones endémicas. El amplio abanico de manifestaciones que van desde asintomáticas a formas fulminantes con compromiso multiorgánico con una alta mortalidad, refuerza la conducta de considerar la leptospirosis como una alternativa cuando se cumplan los criterios mencionados en el desarrollo de esta revisión. De esta manera, cuando el personal de salud entre en contacto con el niño febril, tenga las herramientas para llevar a cabo un diagnóstico temprano y un tratamiento oportuno que permita evitar consecuencias fatales para los pacientes que la padecen.

Agradecimientos: A la diseñadora Alejandra Aranzazu por su aporte en las gráficas del artículo. 


\section{Referencias bibliográficas}

1.- American Academy of Pediatrics. Leptospirosis. In Kimberlin DW, Brady MT, Kimberlin DW, Brady MT, Jackson MA, Long SS, eds. Red Book 2018. Report of the Committee on Infectious Diseases 31st ed: Itaska: Il. American Academy of Pediatrics 2018. pp: 508-11.

2.- Haake D A, Levett P N. 239. Leptospira Species (Leptospirosis). In: Mandell, Douglas, and Bennett's Principles and Practice of Infectious Diseases. Elsevier Inc. Bennett JE, Dolin R, Blaser MJ, eds. Elsevier. Ninenth Edition. Vol. 2; 2019. pp: 2898-2905. e2

3.- Pulido-Villamarín A, Carreño-Beltrán G, Mercado-Reyes M, Ramírez-Bulla P. Situación epidemiológica de la leptospirosis humana en Centroamérica, Suramérica y el Caribe. Univ Sci. 2014;19(3):247-64. doi: 10.11144/ Javeriana.SC19-3.selh

4.- Verdasquera Corcho D, Alpízar García D, Vásquez Pérez A L, Romero Gamboa A L. Galí Bueno L, Abad Lamoth Y, et al. Evaluación del nivel de conocimientos sobre leptospirosis humana en pediatras del hospital William Soler, 2009. Rev Enf Infecc Pediatría. 2011; 24(95): 95-104. https://www.medigraphic.com/pdfs/ revenfinfped/eip-2011/eip111g.pdf

5.- World Health Organization. Report of the Second Meeting of the Leptospirosis Burden Epidemiology Reference Group. World Health Org. 2011; 1-37.

6.- Organización Mundial de la Salud. Leptospirosis humana: guía para el diagnóstico, vigilancia y control. OMS. 2008; 1-127. https://iris.paho.org/bitstream/ handle/10665.2/51096/01016970N12_spa. pdf? sequence $=1$ \&isAllowed $=y$

7.- Organización Panamericana de la Salud. Leptospirosis - Notas Descriptivas. Leptospirosis- notas Descr. 2017; 1-9. https:// www.paho.org/hq/index.php?option=com docman\&view $=$ download\&alias $=39729$ leptospirosis-abril-2017-

729\&category_slug=hoja-informativas$4768 \&$ Itemid $=270 \&$ lang $=e s$

8.- Hartskeerl R A, Collares-Pereira M, Ellis W A. Emergence, control and re-emerging leptospirosis: dynamics of infection in the changing world. Clin Microbiol Infect. 2011;17(4):494-501. doi: 10.1111/j.14690691.2011.03474.x

9.- Cedano J, Rodríguez S, Kujundzic W, Arana J S, Pacheco R, Rosso F. Caracterización clínica de la leptospirosis grave en un hospital de alta complejidad de Cali, Colombia, 2010-2016. Biomédica. 2019;39(1):108-16. doi: 10.7705/ biomedica.v39i2.3985.

10.- Instituto Nacional de Salud (INS). Boletín Epidemiológico Semana: Leptospirosis. INS.
2020; 1-29.

11.- Instituto Nacional de Salud (INS). Protocolo de vigilancia en salud pública: Leptospirosis. INS. 2017; 3:1-15.

12.- Tullu M, Karande S. Leptospirosis in children: A review for family physicians. Indian J Med Sci. 2009; 63(8): 368-78. doi: 10.4103/00195359.55893

13.- Harrison N A, Fitzgerald W R. LeptospirosisCan it be a sexually transmitted disease? Postgrad Med J. 1988 ;64(748): 163-4. doi: 10.1136/pgmj.64.748.163

14.- Agampodi S B, Matthias M A, Moreno A C, Vinetz J M. Utility of quantitative polymerase chain reaction in leptospirosis diagnosis: association of level of leptospiremia and clinical manifestations in Sri Lanka. Clin Infect Dis. 2012; 54(9): 1249-55. doi: 10.1093/cid/ cis 035

15.- Sun A H, Liu X X, Yan J. Leptospirosis is an invasive infectious and systemic inflammatory disease. Biomed J. 2020; 43(1): 24-31. doi: 10.1016/j.bj.2019.12.002:

16.- Cagliero J, Villanueva S Y A M, Matsui M. Leptospirosis pathophysiology: into the storm of cytokines. Front Cell Infect Microbiol. 2018; 8(1): 1-8. doi: 10.3389/fcimb.2018.00204.

17.- Palaniappan R U M, Ramanujam S, Chang Y. Leptospirosis: pathogenesis, immunity, and diagnosis. Curr Opin Infect Dis. 2007;20(2): 284-92. doi: 10.1097/QCO.0b013e32814a5729.

18.- Reis R B, Ribeiro G S, Felzemburgh R D M, Santana F S, Mohr S, Melendez AXTO, et al. Impact of environment and social gradient on Leptospira infection in urban slums. PLoS Negl Trop Dis. 2008; 2 (4): 11-8. doi: 10.1371/ journal.pntd.0000228.

19.- De Brito T, da Silva A M G, Abreu P A E. Pathology and pathogenesis of human leptospirosis: A commented review. Rev Inst Med Trop Sao Paulo. 2018; 60(3): 1-10. doi: 10.1590/S1678-9946201860023.

20.- Feigin. Leptospirosis. 8st ed. Nieves DJ, editor Los Angeles, California: Elsevier; 2020. 1256$1265 \mathrm{p}$.

21.- Gouveia E L, Metcalfe J, De Carvalho A L F, Aires T S F, Villasboas-Bisneto J C, Queirroz A, et al. Leptospirosis-associated severe pulmonary hemorrhagic syndrome, Salvador, Brazil. Emerg Infect Dis. 2008; 14(3): 505-8. doi: 10.3201/eid1403.071064

22.- Haake D A, Levett P N. Leptospirosis in humans, Cur Top Microbiol Immunol. 2015; 387(1): 65-97. doi: 10.1007/978-3-662-4505985.

23.- Wong M L, Kaplan S, Dunkle L M, Stechenberg B W, Feigin R D. Leptospirosis: A childhood disease. J Pediatr. 1977; 90(4): 5327. doi: 10.1016/S0022-3476(77)80361-2

24.- Kobayashi Y. Clinical observation and treatment of leptospirosis. J Infect Chemother. 2001;7 (2): 59-68. doi: 10.1007/ s101560100011.

25.- Fang J Q, Imran M, Hu W L, Ojcius D M, Li $\mathrm{Y}, \mathrm{Ge} \mathrm{Y} \mathrm{M}$, et al. vWA proteins of Leptospira interrogans induce hemorrhage in leptospirosis by competitive inhibition of $\mathrm{vWF} / \mathrm{GPIb}$ mediated platelet aggregation. EBioMedicine. 2018; 37(10): 428-41. doi: 10.1016/j. ebiom.2018.10.033.

26.- Tattevin P, Léveiller G, Flicoteaux R, Jauréguiberry S, Le Tulzo Y, Dupont M, et al. Respiratory manifestations of leptospirosis: A retrospective study. Lung. 2005; 183(4): 283-9. doi: 10.1007/s00408-004-2541-0.

27.- Marchiori E, Lourenço S, Setúbal S, Zanetti G, Gasparetto T D, Hochhegger B. Clinical and imaging manifestations of hemorrhagic pulmonary leptospirosis: A state-of-the-art review. Lung. 2011; 189(1): 1-9. doi: 10.1007/ s00408-010-9273-0.

28.- Pérez-García J, Arboleda M, Flórez P A. Childhood leptospirosis in patients with febrile syndrome in the region of Urabá, Colombia. Rev Peru Med Exp Salud Publica. 2016; 33(4): 745-50. doi: 10.17843/ rpmesp.2016.334.2561

29.- Dupont H, Dupont-Perdrizet D, Perie J L, Zehner-Hansen S, Jarrige B, Daijardin J B. Leptospirosis: prognostic factors associated with mortality. Clin Infect Dis. 1997; 25(3): 720-4. doi: 10.1086/513767.

30.- Marquez A, Djelouadji Z, Lattard V, Kodjo A Overview of laboratory methods to diagnose leptospirosis and to identify and to type leptospires. Int Microbiol. 2017; 20(4): 184-93. doi: 10.2436/20.1501.01.302

31.- Sonthayanon P, Chierakul W, Wuthiekanun $\mathrm{V}$, Thaipadungpanit J, Kalambaheti T, Boonsilp S, et al. Accuracy of loop-mediated isothermal amplification for diagnosis of human leptospirosis in Thailand. Am J Trop Med Hyg. 2011; 84(4): 614-20. doi: 10.4269/ ajtmh.2011.10-0473

32.- Thaipadunpanit J, Chierakul W, Wuthiekanun V, Limmathurotsakul D, Amornchai P, Boonslip $\mathrm{S}$, et al. Diagnostic accuracy of real-time PCR assays targeting 16S rRNA and lipl32 genes for human leptospirosis in Thailand: A case-control study. PLoS One. 2011; 6(1): 1-6. doi: 10.1371/ journal.pone.0016236.

33.- Ahmed A P. Grobusch M. Molecular Approaches in the detection and characterization of Leptospira. J Bacteriol Parasitol. 2012;3(2):1-12. doi: 10.4172/21559597.1000133.

34.- Céspedes M. Leptospirosis: Enfermedad zoonótica emergente. Rev Peru Med Exp Salud Publica. 2005; 22(4): 290-307. http://www. scielo.org.pe/pdf/rins/v22n4/a08v22n4.pdf

35.- Nardone A, Capek I, Baranton G, Campese C, Postic D, Vaillant V, et al. Risk factors for leptospirosis in Metropolitan France: results of a national case-control study, 1999- 
2000. Clin Infect Dis. 2004; 39(5): 751-3. doi: $10.1086 / 423272$

36.- Martínez R, Pérez A, Quiñones M del C, Cruz $\mathrm{R}$, Álvarez Á, Armesto M, et al. Eficacia y seguridad de una vacuna contra la leptospirosis humana en Cuba. Rev Panam Salud Pública. 2004; 15(4): 249-55. doi: 10.1590/s102049892004000400005 .
37.- Andre-Fontaine G, Branger C, Gray A W, Klaasen H L B M. Comparison of the efficacy of three commercial bacterins in preventing canine leptospirosis. Vet Rec. 2003; 2(1): 165 9. doi: 10.1136/vr.153.6.165.

38.- Felix C R, Siedler B S, Barbosa L N, Timm G R, McFadden J, McBride A J A. An overview of human leptospirosis vaccine design and future perspectives. Expert Opin Drug Discov. 2020; 15(2): 179-88. doi: 10.1080/17460441.2020.1694508

39.- Karpagam K B, Ganesh B. Leptospirosis: a neglected tropical zoonotic infection of public health importance-an updated review. Eur J Clin Microbiol Infect Dis. 2020; 39(5): 835-46. doi: 10.1007/s10096-019-03797-4. 